\title{
Sporcularda bel ağrısı: tanı ve tedavi
}

\section{Back pain in athletes: diagnosis and treatment}

\author{
Okan Özkunt $^{1}$, Fatih Dikici ${ }^{1}$, i. Teoman Benli \\ ${ }^{1}$ Acıbadem Üniversitesi, Acıbadem Atakent Hastanesi, Ortopedi ve Travmatoloji Bölümü, İstanbul \\ ${ }^{2}$ Şişli Kolan International Hospital, Okmeydanı, İstanbul
}

\begin{abstract}
Sporcularda görülen bel ağrıları. tekrarlayan mikrotravmalar, akut makro-travma veya kombinasyonları şeklinde oluşabilir. Görülme sıklığı \%1-30 arasında değişkenlik gösterir. Farklı yüklenme mekanizmaları sonrasında, lomber bölgede ortaya çıkan patolojiler değişkenlik gösterir. Erişkin sporcularda meydana gelen bel ağrılarının en sık nedeni, kaslarda ve bağlarda meydana gelen gerilme (strain) ve burkulmadır (sprain). Adolesan yaştaki sporcularda bel ağrısının nedenleri arasında, genellikle lomber bölgeye ait patolojiler, sıklıkla da spondilolizis bulunmaktadır. Erişkin dönemde daha sık görülen disk hastalıklarında, medikal ve fizik tedavi uygulamalarının kombine kullanımı ile başarılı sonuçlar elde edilebilir. Cerrahi tedavi, nörolojik bulguların varlığında veya kısa süreli konservatif tedaviye rağmen iyileşme görülmeyen profesyonel sporcularda uygulanabilir.

Anahtar sözcükler: spor yaralanmaları; bel ağrısı; burkulma ve incinme
\end{abstract}

Back pain common in athletes may occur as repetitive micro-traumas, acute macro-trauma or combination of both. The incidence varies from 1 to $30 \%$. Pathologies appearing in the lumbar region after the different loading mechanisms can be various. Most common causes in adult athletes were strain or sprain of muscles and ligaments. The reasons of low back pain in adolescent athletes are generally pathologies of the lumbar region, and often spondylolysis. Disc disease which occurs more frequently in adulthood can be successfully treated with medical treatment and physiotherapy combined. In the presence of neurological signs or no short-term improvement despite conservative treatment, surgical treatment may be deemed for professional athletes.

Key words: sports injury; low back pain; sprains and strains
B el ağrısı, kas iskelet sistemi sorunları arasında en sık görülen şikayetlerin başında gelir. Normal popülasyonda bel ağrısını inceleyen birçok çalışma olmakla birlikte, sporcularda bel ağrısını irdeleyenlerin sayısı azdır. Sporcuların yüksek aktivite düzeylerine ulaşma çabaları, doğal olarak, bel ağrısı gelişme riskini de arttırmaktadır. Literatürde, sporculardaki bel ağrısı sıklığı \%1-30 arası geniş bir aralıkta bildirilmektedir. ${ }^{[1-4]}$ Omurganın hareket segmentini oluşturan anatomik yapıların her biri ağrı kaynağı olabilir. Bu yapılar; vertebra venöz pleksus, duramater, vertebral arka ait bağlar, kaslar, lamina, apofizyel eklem ve annulus fibrozustur. Provokasyon testleri sonrasında, en sık ağrı kaynağının intervertebral disk ve apofiziyel eklem olduğu gösterilmiştir. ${ }^{[2-3]}$

Bel ağrısının etiyopatogenezinde, omurgaya gelen yüklenmelerin lomber bölgede yarattığı biyomekanik değişiklikler bulunur. Sporcularda meydana gelen bel ağrısında, akut makro-travma, tekrarlayan mikrotravmalar veya bunların kombinasyonu rol oynar. ${ }^{[5]}$ Lomber bölgede disk mesafesine dik gelen kompresif yükler, karın ve paravertebral alanda gerilmeye neden olmaktadır. Vertebra cismi ve son plaklarının kompresif güçlere karşı dayanma gücü, diskten daha azdır. Öne eğilme yüklenmelerinde, fizyolojik sınırlar dışına çıkıldığında, ilk olarak supraspinöz ve interspinöz bağlarda sorun gözlenir. Annulus fibrozusun posterior 1/3-1/2'si, nöral sonlanmalar varlı̆̆ı nedeniyle, ağrıya hassas bölgelerdir. Zorlu öne eğilmelerde, posterior annulus ve apofiziyel eklem kapsülünde yırtıklar meydana gelir. Arkaya zorlu eğilmelerde ise, nöral arkusta sıkışma ile apofiziyel eklemde yaralanma meydana gelebilir. Aksiyel rotasyon$\mathrm{da}$, apofiziyel eklem-kemik kompresyonu, intervertebral bağ gerilmesinden önce oluşur. Eğilme ve kompresyon

- İletişim adresi: Op. Dr. Okan Özkunt, Acıbadem Üniversitesi, Acıbadem Atakent Hastanesi, Ortopedi ve Travmatoloji Bölümü, İstanbul Tel: 0212 - 40444 63, 0532 - 5052620 e-posta: drdeto@gmail.com

- Geliş tarihi: 17 Ağustos 2015 Kabul tarihi: 17 Ağustos 2015 
kuwetlerinin birlikteliğinde, intervertebral diskte posterior prolapsus meydana gelebilmektedir. ${ }^{[6,7]}$

Sporcularda, ilgilendikleri spor dallarına bağlı olarak, lomber bölgeye gelen yüklenmelerde değişiklik olmaktadır. Kürekçilerde fleksiyon ve rotasyonel yüklenme oluşurken, kayakçılarda statik olarak fleksiyon yüklenmesi, jimnastikle uğraşan sporcularda tekrarlayan mikro-travma, futbol ve hentbol oynayanlarda yüksek oranda dönme ve aşırı hareket yüklenmesi, haltercilerde ise lordotik postürde kompresif yüklenmeler meydana gelir (Şekil 1).

Sporcularda bel ağrısının etiyolojileri, yaşa göre farklılık gösterir. Adolesan sporcularda spondilolizis en sık bel ağrısı nedeni iken, erişkinlerde lomber kas ve bağ gerilmeleri ile disk hastalıkları daha sıklıkla görülmektedir (Tablo 1).

\section{SPONDILOLIZis}

Spondilolizis, adolesan dönemde görülen bel ağrılarının en sık nedenlerinden biridir. Spondilolizis,

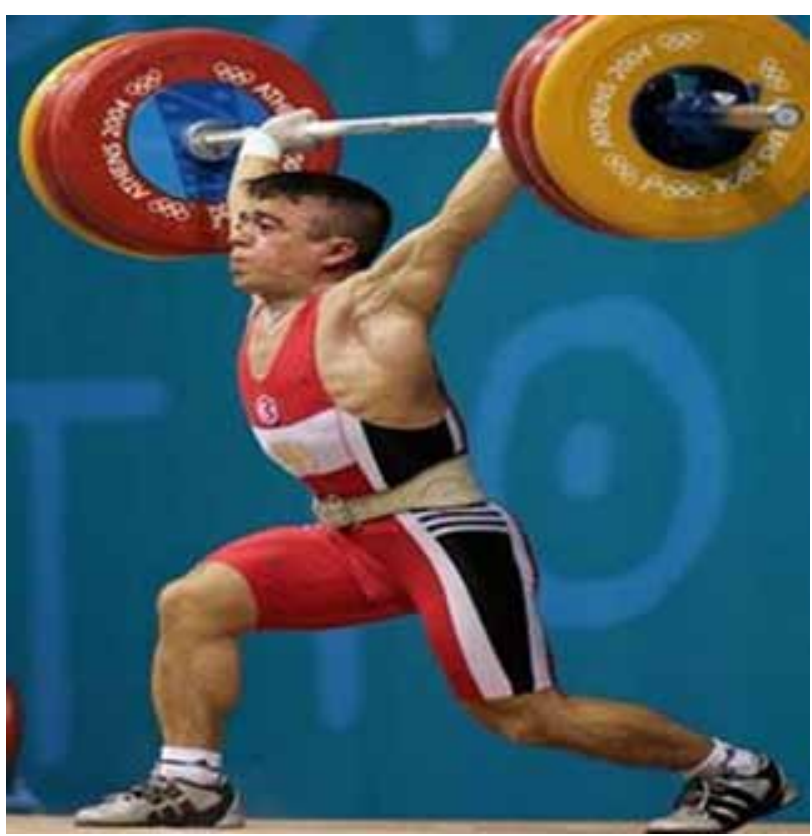

Şekil 1. Haltercilerde olduğu gibi, rotasyonel ve aksiyel kuvvetler, sporcularda bel yaralanmalarının en önemli nedenidir.

Tablo 1. Yaşa bağlı olarak en sık bel ağrısına neden olan tanılar ve oluş mekanizması

\begin{tabular}{|c|c|c|c|c|}
\hline Tanı & Oluş mekanizması & İlgili spor & Adolesan/Erişkin & Bulgular \\
\hline Spondilolizis & $\begin{array}{l}\text { Hiperekstansiyon } \\
\text { Tekrarlayan ekstansiyon }\end{array}$ & $\begin{array}{l}\text { Güreş } \\
\text { Jimnastik } \\
\text { Futbol } \\
\text { Dans } \\
\text { Voleybol }\end{array}$ & Adolesan & $\begin{array}{l}\text { Lokalize bel ağrısı } \\
\text { Hamstring gerginliği }\end{array}$ \\
\hline Spondilolistezis & $\begin{array}{l}\text { Daha önce iyileşmemiş } \\
\text { spondilolizis }\end{array}$ & $\begin{array}{l}\text { Güreş } \\
\text { Jimnastik } \\
\text { Futbol } \\
\text { Dans } \\
\text { Voleybol }\end{array}$ & Adolesan & $\begin{array}{l}\text { Basamaklanma } \\
\text { Hamstring gerginliği } \\
\text { Düz bacak kaldırma testi }\end{array}$ \\
\hline Lomber Scheuremann & $\begin{array}{l}\text { Tekrarlayan Fleksiyonda } \\
\text { Yüklenme }\end{array}$ & $\begin{array}{l}\text { Halter } \\
\text { Amerikan futbolu }\end{array}$ & Adolesan & $\begin{array}{l}\text { Öne eğilme ile artan ağrı } \\
\text { Lokalize bel ağrısı }\end{array}$ \\
\hline $\begin{array}{l}\text { Kırık } \\
\text { (Korpus çökme kırı̆̆ı) } \\
\text { (Son plak kırığı) } \\
\text { (Spinöz çıkıntı Kırı̆ı̆) }\end{array}$ & $\begin{array}{l}\text { Aksiyel yüklenme } \\
\text { Fleksiyonda aksiyel yüklenme } \\
\text { Direkt travma }\end{array}$ & $\begin{array}{l}\text { Travma } \\
\text { Halter } \\
\text { Kayak } \\
\text { Jimnastik } \\
\text { Ekstrem sporlar }\end{array}$ & Adolesan/Erişkin & Ani başlayan ağrı \\
\hline Lomber gerilme/burkulma & $\begin{array}{l}\text { Aşırı kullanma } \\
\text { Kas dengesizliği }\end{array}$ & $\begin{array}{l}\text { Koşu } \\
\text { Halter } \\
\text { Hokey } \\
\text { Futbol } \\
\text { Golf }\end{array}$ & Erişkin & $\begin{array}{l}\text { İstirahatle geçen lokalize bel ağrısı } \\
\text { Aktivite ile ağıı artar }\end{array}$ \\
\hline Disk Hernisi & Rotasyonda aksiyel yüklenme & $\begin{array}{l}\text { Halter } \\
\text { Hokey } \\
\text { Golf } \\
\text { Voleybol }\end{array}$ & Erişkin & $\begin{array}{l}\text { Siyatalji } \\
\text { Kas güçsüzlüğü } \\
\text { Dermatomal his kusuru }\end{array}$ \\
\hline Dar Kanal & $\begin{array}{l}\text { Konjenital ilerleyen darlık } \\
\text { Santral disk hernisi } \\
\text { Dejenerasyon }\end{array}$ & Tüm sporlar & Erişkin & $\begin{array}{l}\text { Fleksiyon postürü } \\
\text { Nörojenik kladikasyon } \\
\text { Aktivite ile ağrıda artış } \\
\text { Kauda sendromu }\end{array}$ \\
\hline
\end{tabular}




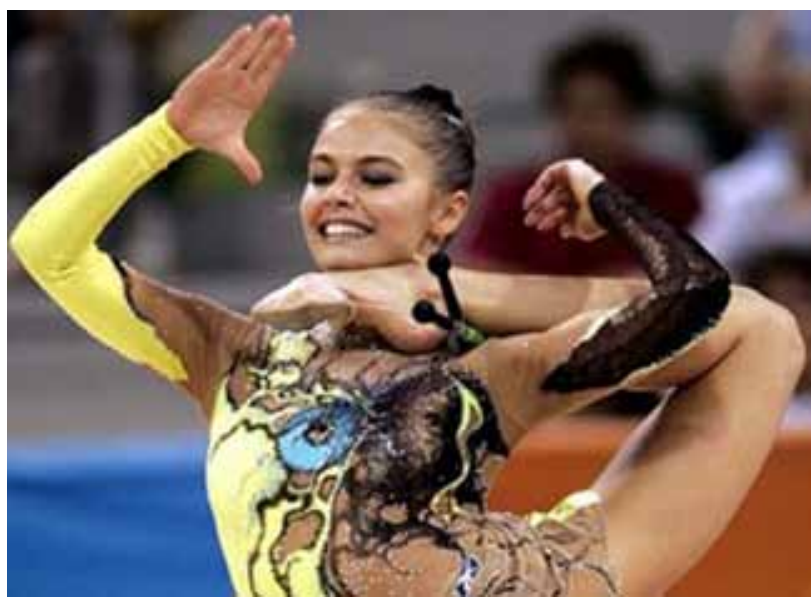

Şekil 2. Jimnastik gibi tekrarlayan hiperekstansiyon aktivitelerinde, interartiküler mesafede aşırı yüklenmelerin meydana getirdiği stres kırıkları rol oynar.

omurun posterior yapılarında, interartiküler mesafede kemiksel eksiklik ile karakterizedir. Tekrarlayan hiperekstansiyon aktivitelerinde (futbol, tenis, jimnastik, dans gibi), interartiküler mesafede aşırı yüklenmelerin meydana getirdiği stres kırıkları rol oynar (Şekil 2). $\cdot^{[1,8]}$

Döngüsel yüklenmelerin, parsta displastik alana sahip olan hastalarda spondilolizise yol açtığı gösterilmiştir. Hutton ve arkadaşları, dakikada 100 siklus uygulanan 570 newton kuvvetin, $1500-54000$ siklus arasında pars kırıklarına yol açtığını göstermişlerdir. Ayrıca, 134 hareketsiz serebral palsili hasta üzerinde yapılan çalışmada, hiç spondilolistezis görülmemiştir. Bu nedenle, küçük yaşta at biniciliği ve atla engel atlama sporu yapan bel ağrılı çocuklarda, spondilolizis akla getirilmelidir (Şekil 3).

Spondilolizise bağlı bel ağrıları, adolesan dönemde \%47 civarında iken, erişkin dönemde \%10 civarındadır ve beyaz erkeklerde siyahlara göre üç kat daha sık görülür. Sporcularda görülme sıklığı \%8-15 arasında bildirilmiştir. Bu oran, spor dallarına göre farklılık gösterir; dansçılarda \%43, atıcı sporcularda $\% 27$, dalgıçlarda \%43, güreşçilerde $\% 30$ insidans bildirilmiştir (Şekil 4). ${ }^{[2,4]}$

Spondilolizis, \%90 oranında L5-S1 segmentinde meydana gelir. Hiperekstansiyon hareketinde en fazla yüklenmenin L5-S1 segmentinde olması, buna neden olarak gösterilebilir. Spondiloliziste, Wiltse tarafından önerilen sınıflama kullanılmaktadır. Buna göre; Tip 1, displastik; Tip 2, istmik (A, stres kırı̆̆ı; B, elongasyon; C, akut kırık); Tip 3, dejeneratif; Tip 4, postravmatik; Tip 5, patolojik olarak sınıflandırılmaktadır. ${ }^{[9]}$

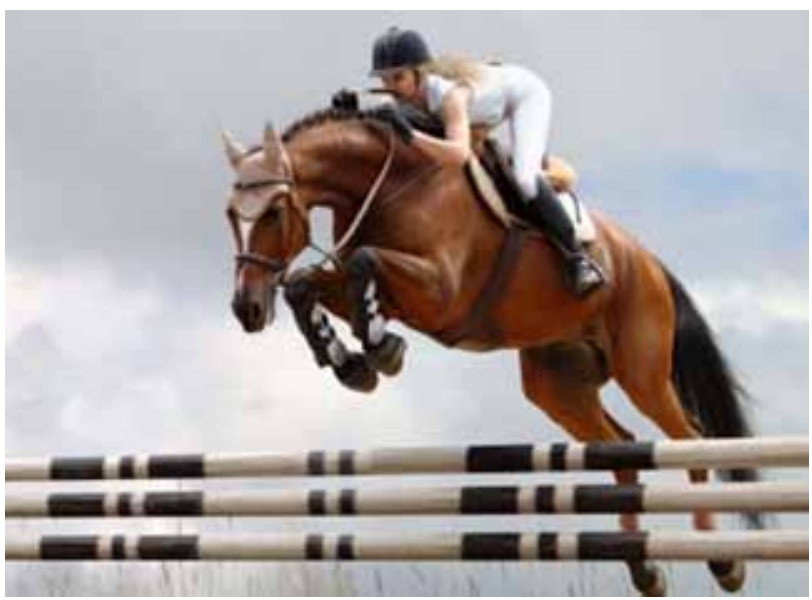

Şekil 3. Küçük yaşta at biniciliği ve atla engel atlama sporu yapan bel ağrılı çocuklarda, spondilolizis akla getirilmelidir.

Spondilolizis olgularının birçoğu asemptomatik olmakla beraber, yüksek spor aktivitesine sahip sporcularda semptomatik seyredebilir. Sporcular, genellikle lokalize bel ağrısı ve kalçalara yayılan ağrıdan şikayetçi olmaktadır. Nadir olgularda, bu patolojiye radiküler ağıı da eşlik edebilmektedir. İlerlemiş olguların $\% 80$ 'inde hamstring gerginliği bulunabilir. ${ }^{[4,8,10]}$

Tanıda, standart radyografiye ek olarak, her iki oblik grafide interartiküler mesafeyi gösteren "Scottie dog" (İskoç köpeği) görüntüsü elde edilmelidir. Scottie dog görüntüsünde, köpeğin boynunda ya da yakasında kırık ile pars defekti olması tanıda çok önemlidir. Erken dönem olguların direkt radyografilerinde bulgu saptanmazsa, ileri tetkiklere ihtiyaç duyulabilir (Şekil 5).

Radyografik bulgusu olmayan hastalarda, kemik sintigrafisi yararlı olabilir. Sintigrafide, osteoblastik aktivitenin artması ile yüksek metabolik aktivite gözlenirken, kaynamama veya defekt olan alanlarda düşük metabolik aktivite (cold in hot spot) görülür. Ince kesit

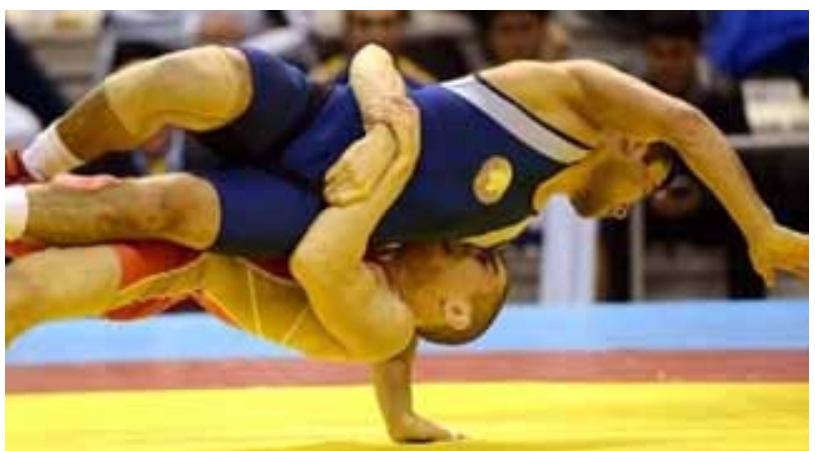

Şekil 4. Güreşçilerde \%30 insidans bildirilmiştir. 

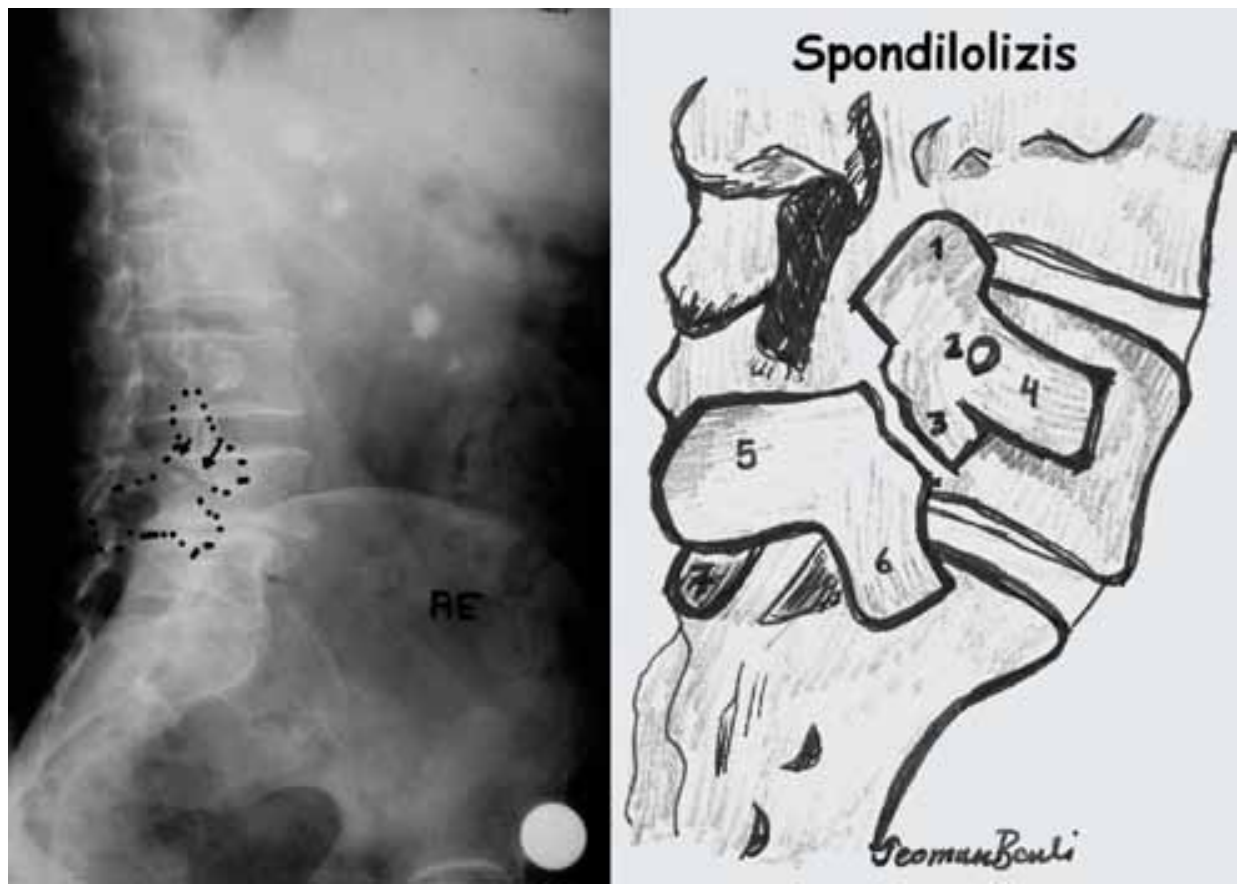

Şekil 5. Scottie dog görüntüsünde, köpeğin boynunda ya da yakasında kırık ile pars defekti olması, tanıda çok önemlidir.

bilgisayarlı tomografi (BT) tanıda değerlidir; ancak, ek yumuşak doku ve disk hastalıkları hakkında, manyetik rezonans (MR) görüntüleme daha fazla bilgi verir.

Tedavide amaç, kaynamayı sağlamak, ağrıyı azaltmak ve fonksiyonel aktiviteyi arttırmaktır. Asemptomatik sporcuların tedavisinde takip önerilirken, semptomatik hastalarda öncelikle konservatif tedavi yöntemleri denenmelidir. ${ }^{[8,11]}$ Tek taraflı olgularda breys kullanımı ile \%78 iyileşme gözlenirken, bilateral olguların ancak \%8'inde iyileşme bildirilmiştir. [3] Breys tedavisi ve medikal tedavi modifikasyonları ile, kaynama süresi 3-12 ay arasında değişmektedir. ${ }^{[3,7]}$ Cerrahi tedavi, semptomatik olgularda veya belirgin spondilolistezis olgularında uygulanır. Cerrahi tedavi seçenekleri arasında, pars tamiri veya tek seviyeli füzyon vardır. Pars tamiri, dejenere disk hastalığı ve spondilolistezi olmayan orta derecede pars defektlerinde tercih edilmelidir.

\section{PARAVERTEBRAL GERILME (STRAIN) VE BURKULMA (SPRAIN)}

Genç sporcuların aksine, erişkin sporculardaki bel ağrısının etiyolojisinde genellikle patolojik bir neden bulunamaz. Bel ağrısının etiyolojisinde, kasta gerilme ve bağlarda burkulma vardır. Paravertebral gerilme ve burkulmalar, adolesan dönemindeki bel ağrılarının ancak \%6'sında gösterilebilmiştir. Erişkin sporculardaki bel ağrısına, sıklıkla mekanik faktörler neden olmaktadır. Büyüme atakları, oransız büyüme, kas ve bağların gelişmesindeki gerilikler de ağrılara neden olabilir. ${ }^{[12]}$

Paravertebral gerilme ve burkulmalarda tanısal testler çok yardımcı olmamakla beraber, iki hafta içerisinde hastaların şikayetlerinde yüksek oranda düzelme izlenir. Bono ve arkadaşları, yaptıkları çalışmada, bel ağrısı ile başvuran sporcularda \%41-59 oranında akut veya kronik olarak gelişen burkulma ve gerilme olduğunu göstermiş̧lerdir (Şekil 6). ${ }^{[3]}$

Paravertebral gerilme ve burkulmanın nedenleri arasında; kas dengesizlikleri, alt ekstremite biyomekanik bozuklukları ve azalmış esneklik sayılabilir. Sporcunun yapılan muayenesinde, lomber bölgede lokal hassasiyet ve tekrarlayan hareketlerde ağrı saptanır. Bel ağrısı olan hastalarda, paravertebral kaslarda elle muayene ile hassasiyet saptanırken, nörolojik muayenede bu özellik yoktur.

Tanı ve tedavide, sporcu olmayan popülasyonda ek tetkik yapilmadan analjezik tedavi ve istirahat yeterli olurken, sporcularda tekrarlayan travmaların varlığı, direkt röntgen çekimini gerekli kılar. Sporcularda tekrarlayan bel ağrılarının engellenmesi için, lomber stabilizasyonu arttıran bel ve sırt kaslarını kuvvetlendiren egzersizler yapılması gerekmektedir. 


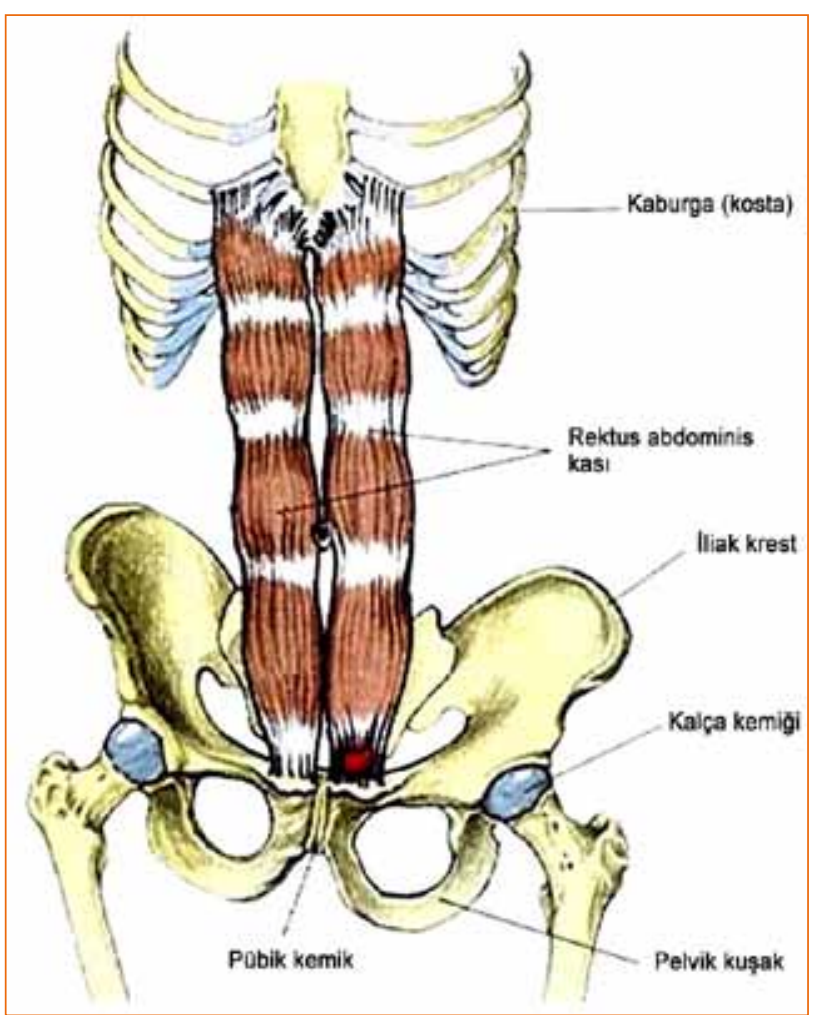

Şekil 6. Bel ağrısının etiyolojisinde, kasta gerilme ve bağlarda burkulma vardır.

\section{DISK HASTALIKLARI}

Vertebral disk, jel kıvamında nükleus fibrozusun, sıkı kollajen yapıda annulus fibrozus tarafindan çevrilmesi ile meydana gelir. Zayıf olan disk fitıklaşarak, nöral yapılara bası yapabilmektedir. İntervertebral disk, içindeki su oranı ve elastik yapısı ile kompresif yüklere dayanıklı iken, annulus fibrozusun çapraz bağlı yapısı nedeniyle, rotasyonel yüklenmelere direnç gösterir. Disk içeriğindeki değişimler, dayanıklılığı etkiler. Disk hernisinde esas patolojiyi, kompresyon, öne fleksiyon ve rotasyonel kuvvetlerin kombine etkileri oluşturur. ${ }^{[13]}$ Futbol, güreş, tenis, hokey, golf ve jimnastik, bu yüklenmelerin en fazla olduğu spor dallarıdır. ${ }^{[13]}$

Disk hastalıkları, genç sporcularda nadir (\%11) olmakla beraber, erişkin sporcularda daha sıklıkla (\%48) meydana gelir. Genç hastalarda meydana gelen disk hastalıkları, diskin kemiğe göre biyomekanik yüklenmelere daha dirençli olmasından dolayı, son plağın veya apofizin içerisine fitıklaşma şeklinde olmaktadır. [7] Genç sporcularda, nadiren posterior fitıklaşma meydana gelir ve nöral yapılarda bası oluşur. Illeri olmayan olgularda, konservatif tedavi yöntemleri yeterlidir. Cerrahi tedavi, konservatif yöntemlerle cevap alınamayan durumlarda düşünülmelidir.
Disk hastalıkları açısından, 22-35 yaş arası sporcular risk altındadır. L5-S1 intervertebral diski, en sık etkilenen bölgedir. Öne eğilme ile arkaya doğru yer değiştiren disk, ağrıya neden olur. Bu nedenden ötürü, disk hastaları lomber bölgeyi ekstansiyonda koruma eğilimindedirler. Disk hernisi sonrası, ilgili dermatomda his kusuru ve motor alanda güç kaybı meydana gelebilir. Santral fitıklarda; öksürme, valsalva gibi intratekal basıncı arttıran durumlarda, hastanın şikayetlerinde artma meydana gelir. Disk hastalıklarında ağrı, sadece protrüzyon sonrası meydana gelmez; diskin posteriorundaki dejenerasyonlar da, buradaki nöral sonlanmaların varlığıyla, ağrı oluşumuna neden olur. İlerlemiş olgularda, idrar ve gaita inkontinansı ile giden ve acil tedavi gerektiren "cauda equina" sendromu meydana gelebilir.

Fizik muayenede, düz bacak kaldırma testi pozitifliği, nörolojik olarak etkilenen kasta güç ve/veya duyu kaybı meydana gelir. Tanıda MR, disk patolojisi ve sinir köklerindeki bası durumunu daha iyi ortaya koyabilir. Elektromiyografi ise, sinirin fonksiyonel durumunu gösterir.

Etkilenen sporcularda nörolojik bulgu yok ise, konservatif tedavi yöntemleri yeterli olacaktır. Konservatif tedavide kabul edilen aşamalı yaklaşım; Faz 1, ağrı kontrolü ve aktivite modifikasyonu; Faz 2, dinamik spinal stabilizasyon egzersizlerine başlanması; Faz 3, bel kaslarını kuvvetlendirici egzersizlere başlanması; Faz 4, spora özgü egzersiz programına başlanması; Faz 5, tekrarlayan bel ağrılarını azaltmak için mevcut egzersizlere devam edilmesi şeklinde sıralanabilir. ${ }^{[14]}$ Hastalığın şiddetine göre, tedaviye başlanılacak aşama farklılık gösterebilir.

Tek seviyeli disk hernilerinde, cerrahi tedaviyle başarılı sonuçlar elde edilir. Şikayetleri 4-6 ay arası konservatif tedaviye rağmen geçmeyen hastalarda, tek seviyeli füzyon önerilmektedir. Tek seviyeli füzyon sonrası, spora dönüşlerde ve aktivite düzeylerinde herhangi bir kısıtlanma meydana gelmez. ${ }^{[14]}$

\section{VERTEBRA KIRIKLARI}

Aşırı aksiyel yüklenmeler sonrası, vertebralarda kompresyon kırıkları meydana gelebilir. Adolesan dönemde meydana gelen kırıklar, son plak kırıkları şeklinde görülürken, erişkin dönemde vertebra cisimlerinde çökme kırıkları şeklinde olmaktadır. Kırıklar sıklıkla torakolomber geçiş bölgesinde, birinci lomber omurda meydana gelir. Kırık kliniğinde, egzersiz veya travma sonrasında ani başlayan ağrı vardır. Fizik muayenede, noktasal ağrı ve interspinöz aralıkta palpasyonla basamaklanma bulunabilir.

Spinöz proses kırıkları, direkt travma ile meydana gelebileceği gibi, adolesan sporcularda, ekstansör kas 


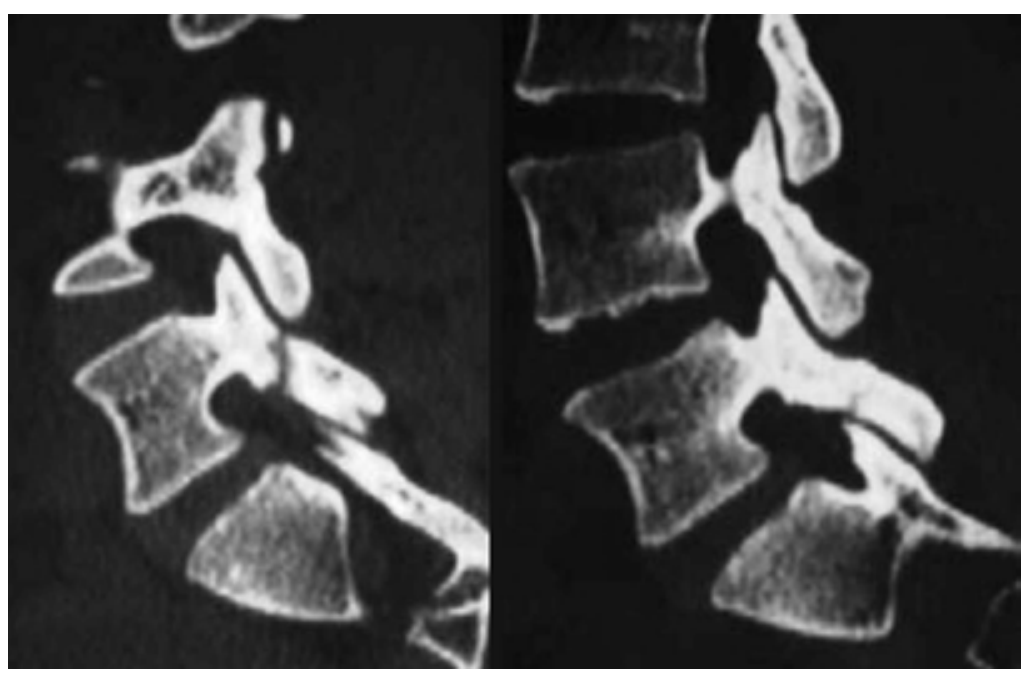

Şekil 7. Kadın sporcularda, alt lomber bölge ağrılarının nedenleri arasında, nadir olarak sakral stres kırıkları olabilir.

gruplarının aşırı kontraksiyonu sonrasında, spinöz çıkıntı apofızinin avulsiyon kırığı şeklinde de olabilir.

Konservatif tedavide, ağrı geçene kadar breys kullanımı önerilir. Spora dönüş, tam iyileşme ve kaynama elde edilene kadar, ortalama iki ay sürebilir. Kompresyon kırıklarının ileri safhalarında, instabilite varlığında veya $20^{\circ}$ 'den fazla lokal kifoz açılanması varsa, cerrahi tedavi gerekir.

Kadın sporcularda, alt lomber bölge ağrılarının nedenleri arasında, nadir olarak sakral stres kırıkları olabilir (Şekil 7). Genellikle osteoporotik yaşıların kırı̆̆ı olarak bilinen bu kırıklar, tekrarlayan travmalar sonrası aşırı kullanıma bağlı olarak oluşur. Fizik muayenede Patrick testi pozitif iken, etkilenen taraf üzerinde zıplama ile artan ağrı vardır. Osteoporoz, risk faktörü olduğundan, mutlak surette araştırılmalıdır. Tedavide; patolojinin düzeltilmesi, yükten kurtarma ve ağrı kontrolü vardır.

\section{TARTIŞMA}

Sporcularda bel ağrısının nedenleri farklılık gösterir. On iki yaş altı sporcularda bel ağrısı görülme sıklığı $\% 12$ civarındayken, etiyolojide \%45-50 oranında patolojik bir durum saptanmaktadır. Bu yaş grubundaki sporcularda, en sık spondilolizis görülmekle beraber, spondilolistezis, lomber Scheuermann hastalığı, skolyoz, transvers veya spinöz çıkıntı kırıkları da görülebilir. Bu yaş grubunda nadir görülen disk hernisi, bel ağrısı ile kendini gösterebilir.

Erişkin yaştaki sporcularda meydana gelen bel ağrılarının en sık nedeni, genellikle mekanik yüklenmeler sonrasında paravertebral kaslarda ve bağlarda meydana gelen incinmelerdir. Disk hernisi, kompresyon kırıkları, spinal stenoz ve dejeneratif değişiklikler, bel ağrısına neden olabilecek diğer patolojilerdir.

Bel ağrısı olan hastalarda, mekanik bel ağrısının ayırıcı tanısı yapılmalıdır. Bel ağrısı ile başvuran sporcularda; ağrının karakteri, yerleşimi, yayılımı, başlangıç şekli ve zamanı gibi, bel ağrısını arttıran durumlar iyi kaydedilmelidir. Ağrının değerlendirilmesinde, yansıyan ağrı olabileceği göz önünde bulundurulmalı, vasküler ve visseral organ patolojileri muhakkak taranmalıdır.

Bel ağrısının değerlendirilmesinde sorgulanması gereken ve kırmızı bayrak olarak bilinen, ateş, kızarıklık, gece ağrısı ve terlemesi, kilo kaybı gibi bulgular, enfeksiyöz ya da malign hastalıklar için uyarıcı olmalıdır.

Tanıda görüntüleme yöntemlerine başvurulması, sporcu olmayan popülasyonda altı haftalık konservatif tedaviye yanıt alınamaması durumunda önerilmekte iken; sporcularda, tekrarlayan travmalar nedeniyle, erken dönemde görüntülemeye başvurulmalıdır. Sporcularda yapılan çalışmalarda, spinal patolojilerin normal popülasyona göre daha sık olduğu gösterilmiştir. ${ }^{[15,16]}$ Standart çekilen ön-arka ve yan grafiler, majör patolojileri saptamakta yeterli olabilmekle beraber; oblik ve dinamik lateral grafilerinin eklenmesi, tanıda yardımcı olabilir. İleri görüntüleme yöntemi olarak, direkt radyografilere göre daha duyarlı olan MR uygulanmaktadır. MR ile, dejeneratif ve yumuşak dokuda meydana gelen değişiklikler daha hassas olarak değerlendirilir.

Tedavide, istirahat ilk tedavi yaklaşımı olarak kullanılır; beraberinde, özel egzersiz programı ile 
kuvvetlendirici ve stabilize edici egzersizler yarar sağlamaktadır. Sporcularda uzun dönemli yatak istirahati, eklem sertliği ve kas zayıflığı yaratabileceğinden, iki günü geçmeyecek şekilde önerilmektedir.

Konservatif tedavi yöntemleri içerisinde, ağrı modifikasyonunu sağlayan steroid dişı anti-inflamatuvar ve kas gevşetici ilaç kombinasyonlarının kullanılması önemlidir. Yapılan çalışmalarda, bu ilaçların en az iki hafta kullanıldığında etkin tedavi sağladığı gösterilmiştir. ${ }^{[17]}$ Uzun süreli kronik bel ağrısı olan hastalar$\mathrm{da}$ ise, asetaminofen ve tramadol kombinasyonları kullanılmaktadır.

Faset eklem, foraminal ve tetik nokta enjeksiyonları, ağrı tedavisinde kullanılabilecek diğer yöntemlerdir. Manipülasyon tedavisinin plaseboya göre etkinliği gösterilmekle beraber, bu da aşamalı egzersiz tedavisine benzer sonuçlara sahiptir. Günümüzde, kronik bel ağrısı varlığında kombine tedavi uygulamaları, tekrarlayan bel ağrılarını önlemektedir. ${ }^{[18]}$

Cerrahi tedavi, genç sporculardan ziyade, erişkin sporcularda uygulanmaktadır. Nörolojik defisit ile beraber olan fitıklarda, kanal darlıklarında ve semptomatik spondilolistezis olgularında, cerrahi tedavi tercih edilir.

\section{KAYNAKLAR}

1. McCarroll JR, Miller JM, Ritter MA. Lumbar spondylolysis and spondylolisthesis in college football players. A prospective study. Am J Sports Med 1986;14(5):404-6.

2. Burgmeier RJ, Hsu WK. Spine surgery in athletes with low back pain considerations for management and treatment. Asian J Sports Med 2014;5(4):e24284. CrossRef

3. Bono CM. Low-back pain in athletes. J Bone Joint Surg Am 2004;86-A(2):382-96.
4. Baker RJ, Patel D. Lower back pain in the athlete: common conditions and treatment. Prim Care 2005;32(1):201-29.

5. Kujala UM, Taimela S, Erkintalo M, Salminen JJ, Kaprio J. Low-back pain in adolescent athletes. Med Sci Sports Exerc 1996;28(2):165-70.

6. Adams MA, Freeman BJ, Morrison HP, Nelson IW, Dolan $P$. Mechanical initiation of intervertebral disc degeneration. Spine (Phila Pa 1976) 2000;25(13):1625-36.

7. Adams MA. Biomechanics of back pain. Acupunct Med 2004;22(4):178-88.

8. Stinson JT. Spondylolysis and spondylolisthesis in the athlete. Clin Sports Med 1993;12(3):517-28.

9. Wiltse LL, Winter RB. Terminology and measurement of spondylolisthesis. J Bone Joint Surg Am 1983;65(6):768-72.

10. Standaert CJ. Low back pain in the adolescent athlete. Phys Med Rehabil Clin N Am 2008;19(2):287-304. CrossRef

11. Standaert CJ, Herring SA, Halpern B, King O. Spondylolysis. Phys Med Rehabil Clin N Am 2000;11(4):785-803.

12. Greydanus DE, Patel DR. Back pain in the adolescent athlete. Asian Journal of Paediatric Practice 2000;3(4):83-94.

13. O'Conner R, Andary MT. Herniated nucleus pulposus. In: Bracker MD, editor. The 5-minute Sports Medicine Consult. Philadelphia: Lippincott, Williams \& Wilkins; 2001. p.190-1.

14. Cooke PM, Lutz GE. Internal disc disruption and axial back pain in the athlete. Phys Med Rehabil Clin N Am 2000;11(4):837-65.

15. Swärd L, Hellström M, Jacobsson B, Nyman R, Peterson L. Disc degeneration and associated abnormalities of the spine in elite gymnasts. A magnetic resonance imaging study. Spine (Phila Pa 1976) 1991;16(4):437-43.

16. Hellström M, Jacobsson B, Swärd L, Peterson L. Radiologic abnormalities of the thoraco-lumbar spine in athletes. Acta Radiol 1990;31(2):127-32.

17. Tudler M, Koes B. Low back pain and sciatica (acute). In: Godlee F, editor. BMJ clinical evidence concise. Kingsport (UK): BMJ Publishing Group; 2003. p.237-9.

18. Department of Veterans Affairs. Low back pain or sciatica in the primary care setting. Washington (DC): Department of Veteran's Affairs, Veteran's Health Administration, Office of Quality and Performance; 1999. 